medRxiv preprint doi: https://doi.org/10.1101/2021.06.22.21259315; this version posted June 25,2021 . The copyright holder for this preprint

(which was not certified by peer review) is the author/funder, who has granted medRxiv a license to display the preprint in perpetuity.

All rights reserved. No reuse allowed without permission.

\title{
Ilioinguinal versus modified Stoppa approach for open reduction and internal fixation of displaced acetabular fractures: A Protocol for Systematic Review and Meta-Analysis
}

\section{Contributors}

1. Amit Srivastava, MS, Assistant professor, Department of Orthopaedics, University College of Medical Sciences and G T B Hospital, Delhi, India.

2. Rajesh Kumar Rajnish, MS, Assistant professor, Department of Orthopaedics, All India Institute of Medical Sciences, Bilaspur, Himachal Pradesh, India.

3. Prasoon Kumar, MS, Assistant professor, Department of Orthopaedics, Postgraduate Institute of Medical Education and Research, Chandigarh, India

4. Rehan Ul Haq, MS, Department of Orthopaedics, Professor All India Institute of Medical Sciences, Bhopal, India

5. Ish Kumar Dhammi, MS, Senior Specialist, Department of Orthopaedics, University College of Medical Sciences and G T B Hospital, Delhi, India.

Amendments: none

Conflicts of Interest: None

Sources of Support/Funding: None

Contributions: AS, RKR, RUH, and IKD conceptualized the review protocol and provided critical inputs for formulating the key protocol elements. AS and RKR planned the search strategy. AS and, RKR wrote the manuscript, and PK proofread it. Finally, all the authors approved the final version of the protocol.

Correspondence to: Dr. Rajesh Kumar Rajnish. Department of Orthopedics, All India Institute of Medical Sciences, Bilaspur, Himachal Pradesh, India. 174001

Email: duktiraj@gmail.com

NOTE: This preprint reports new research that has not been certified by peer review and should not be used to guide clinical practice. 


\title{
Ilioinguinal versus modified Stoppa approach for open reduction and internal fixation of displaced acetabular fractures: A Protocol for Systematic Review and Meta-Analysis
}

\begin{abstract}
Background:

The fracture of the acetabulum is one of the most challenging fractures to manage and operate for orthopaedic surgeons. To get a good surgical outcome, anatomical reduction of fractures and reconstruction of the joint is of utmost importance. To achieve a good postoperative outcome an appropriate surgical approach is necessary to achieve an anatomical reduction of fractures and fewer complications.
\end{abstract}

Objective: The current review aims to compare the outcomes of the ilioinguinal versus modified Stoppa approach for open reduction and internal fixation (ORIF) of displaced acetabular fractures by analyzing the evidence from the current literature.

\section{Methods:}

A systematic review of the literature will be conducted in accordance with the PRISMA guidelines. The primary searches will be conducted on the Medline (PubMed), Embase, Scopus, and Cochrane Library databases, using a pre-defined search strategy. The studies of any design in the English language will be included which compared the outcomes of the ilioinguinal and modified Stoppa approach for ORIF of displaced acetabular fractures and reported at least one outcome of interest. Studies that do not compare the outcomes of the ilioinguinal and modified Stoppa approach for the treatment of displaced acetabular fractures in adults ( $>18$ years of age), case reports, conference abstracts, posters, book chapters, review articles, biomechanical studies, technical tips, cadaveric studies, and articles not in the English language will be excluded. Both qualitative and quantitative analyses will be done. Qualitative analysis will be done using appropriate tables and diagrams. Wherever feasible, quantitative analysis to be done with the appropriate software. The risk-of-bias assessment will be done using the MINORS tool for the non-randomized comparative studies, and The Cochrane Collaboration's risk-of-bias tool will be used for randomized control trials.

Keywords: acetabular fractures; ilioinguinal approach; modified Stoppa approach; meta-analysis. 


\section{Background}

Acetabulum fracture is one of the most challenging intraarticular fractures to manage and operate for orthopaedic surgeons, to get a good surgical outcome, anatomical reduction of fractures and reconstruction of the joint are of utmost importance. [1] To achieve this an appropriate surgical approach is necessary to minimize complications. [2,3]

The ilioinguinal approach is widely used for the fixation of the pelvis and acetabular fractures, it has been found effective in approaching most of the anterior acetabular fracture patterns. [3-5] However, this exposure is a quite extensive approach and poses risk to the neurovascular structures present in proximity, and other soft tissue related complications. [5-7] While the modified Stoppa intrapelvic approach is considered to be less invasive, avoids the middle window of the ilioinguinal approach and gives better exposure of the quadrilateral plate, medial wall of the acetabulum, and sacroiliac joint. This approach requires identification of the corona mortis and its ligation to prevent excessive bleeding, however, there is a risk of the obturator nerve and superior gluteal artery injury. [8-9]

\section{Need for review}

There are several published literature that compared the clinical outcome and complications of the ilioinguinal and modified Stoppa approach however only a few authors have conducted a systematic review or meta-analysis to compare the outcome of the approaches. [10-12] Therefore, the current review aims to perform a systematic review and meta-analysis from current literature to compare the outcomes of the ilioinguinal versus modified Stoppa approach for ORIF of the anterior pelvic ring and acetabular fractures.

\section{Objectives}

Primary Objectives:

i) To compare the primary outcomes like duration of surgery, anatomical reduction quality, total and individual complications for the ilioinguinal and modified Stoppa approach used for the ORIF of displaced acetabular fractures.

Secondary Objective:

i) Additionally, to compare the intraoperative blood loss, and clinical outcomes for both the surgical approaches.

\section{PICO framework for the study}

i) Participants: a human subject with displaced acetabulum fractures 
ii) Intervention: Ilioinguinal approach for the open reduction and internal fixation of acetabulum fracture

iii) Control: modified Stoppa approach for the open reduction and internal fixation of acetabulum fracture

iv) Outcomes: The primary outcomes of interest will be the mean duration of surgery, anatomical reduction quality, total and individual complications (vascular injury, nerve injury, infection, and heterotopic ossification). The secondary outcomes of interest will be intraoperative blood loss and clinical outcomes.

\section{Methods}

This systematic review and meta-analysis will be conducted in accordance with the Preferred Reporting Items for Systematic Reviews and Meta-analysis guidelines (PRISMA). [13]

i) Review Protocol: A protocol of the review will be formulated in priority in accordance with the PRISMA-P guidelines. (Appendix I)

Eligibility Criteria: The studies of any design in the English language will be included that compared the outcomes of the ilioinguinal approach and modified Stoppa approach for the treatment of displaced acetabular fractures and reported at least one outcome of interest. Studies that do not compare the outcomes of the ilioinguinal and modified Stoppa approach for the treatment of acetabular fractures in adults ( $>18$ years of age), case reports, conference abstracts, posters, book chapters, review articles, biomechanical studies, technical tips, cadaveric studies, and articles not in the English language will be excluded.

iii) Information Sources \& Literature search: A primary literature search will be conducted on the Medline (PubMed), Embase, Scopus, and Cochrane Library databases, using a pre-defined search strategy (Table-1). A manual secondary search of references from the full-text of all included articles and relevant review articles will be conducted. There will be no initial restrictions on the date or language of publication.

All the identified articles will be screened through titles and abstracts for eligibility independently by three authors. After initial screening, full texts of all selected articles will be obtained. Eligible articles will be sorted as per the prespecified inclusion and exclusion criteria. The reasons for the exclusion of those articles for which full-text was obtained will be documented. Any discrepancies in the article selection process will be resolved by mutual agreement. 

two authors independently, a third author will cross-check the data for accuracy. Baseline data items will include:

- Name of the authors and year of publication

- Number of patients/cases

- Study design

- Surgical approach used

- Number of patients in each group

- Mean age of the patients

- Sex of the patients

- Mean follow up

- Primary outcomes and

- Secondary outcomes of interest.

vi) Outcome Measures: The following outcome measures will be evaluated however addition and/or modifications will be made if needed:

- The primary outcomes of interest will be the mean duration of surgery, anatomical reduction quality, total and individual complications (vascular injury, nerve injury, infection, and heterotopic ossification).

- The secondary outcomes of interest will be intraoperative blood loss and clinical outcomes.

vii) Data Analysis and Synthesis:

Both qualitative and quantitative data analysis will be performed. For qualitative data analysis, appropriate tables and data visualization diagrams will be used.

Quantitative analysis will be performed if $\geq 2$ studies included in this review, reported the values of either of the primary or secondary outcomes of interest. To describe the measure of treatment effects, the mean difference will be used for continuous variables, and odds ratio will be used for dichotomous variables. All the results will be expressed along with $95 \%$ confidence intervals. Forest plots will be constructed to visualize the results. The statistical heterogeneity will be determined by using the $\mathrm{I}^{2}$ test. Reasons for clinical heterogeneity, if any, will be explored. If the heterogeneity was low $\left(\mathrm{I}^{2}<75 \%\right)$ fixed-effects model, otherwise the randomeffects model $\left(\mathrm{I}^{2}>75 \%\right)$ will be used. Meta-analysis will be performed by using Review Manager Software version 5.4. [14] 
medRxiv preprint doi: https://doi.org/10.1101/2021.06.22.21259315; this version posted June 25, 2021. The copyright holder for this preprint (which was not certified by peer review) is the author/funder, who has granted medRxiv a license to display the preprint in perpetuity.

All rights reserved. No reuse allowed without permission.

viii) Assessment of Risk of Bias: The risk-of-bias assessment will be done using the MINORS tool for the non-randomized comparative studies [15], and the Cochrane Collaboration's risk of bias tool [16] will be used for randomized control trials

\section{References}

1. Kacra BK, Arazi M, Cicekcibasi AE, Buyukmumcu M, Demirci S.Modified medial Stoppa approach for acetabular fractures: an anatomic study. J Trauma. 2011;71(5):1340-4.

2. Letournel E. The treatment of acetabular fractures through the ilioinguinal approach. Clin Orthop Relat Res. 1993;(292):62-76.

3. Letournel E. Fractures of the acetabulum. A study of a series of 75 cases. 1961. Clin Orthop Relat Res. 1994;(305):5-9.

4. Giannoudis PV, Kanakaris NK, Dimitriou R, Mallina R, Smith RM. The surgical treatment of anterior column and anterior wall acetabular fractures: short- to medium-term outcome. J Bone Joint Surg Br. 2011;93(7):970-4.

5. Seyyed Hosseinzadeh HR, Eajazi A, Hassas Yeganeh M, et al. Modified ilioinguinal approach to the acetabulum and pelvis from beneath the inguinal ligament: a subinguinal approach. Hip Int. 2010;20(2):150-5.

6. Gansslen A, Krettek C. Internal fixation of acetabular both-column fractures via the ilioinguinal approach. Oper Orthop Traumatol. 2009;21(3):270-82.

7. Matta JM. Operative treatment of acetabular fractures through the ilioinguinal approach: a 10-year perspective. J Orthop Trauma.2006;20(1 Suppl): S20-9.

8. Ponsen KJ, Joosse P, Schigt A, Goslings JC, Luitse JS. Internal fracture fixation using the Stoppa approach in pelvic ring and acetabular fractures: technical aspects and operative results. J Trauma. 2006;61(3):662-7.

9. Sagi HC, Afsari A, Dziadosz D. The anterior intra-pelvic (modified rives-stoppa) approach for fixation of acetabular fractures. J Orthop Trauma. 2010;24(5):263-70. 
medRxiv preprint doi: https://doi.org/10.1101/2021.06.22.21259315; this version posted June 25, 2021. The copyright holder for this preprint (which was not certified by peer review) is the author/funder, who has granted medRxiv a license to display the preprint in perpetuity.

All rights reserved. No reuse allowed without permission.

10. Shazar N, Eshed I, Ackshota N, Hershkovich O, Khazanov A, Herman A. Comparison of acetabular fracture reduction quality by the ilioinguinal or the anterior intrapelvic (modified Rives-Stoppa) surgical approaches. J Orthop Trauma. 2014;28(6):313-9.

11. Meena S, Sharma PK, Mittal S, et al. Modified Stoppa approach versus ilioinguinal approach for anterior acetabular fractures; a systematic review and meta-analysis. Bulletin of Emergency and Trauma 2017; 5:6-12.

12. Wu H, Zhang L, Guo X, Jiang X. Meta-analysis of modified Stoppa approach and ilioinguinal approach in anterior pelvic ring and acetabular fractures. Medicine (Baltimore). 2020;99(4):e18395.

13. Page MJ, McKenzie JE, Bossuyt PM, Boutron I, Hoffmann TC, Mulrow CD, et al. The PRISMA 2020 statement: an updated guideline for reporting systematic reviews. BMJ. 2021;372:n71.

14. Review Manager (RevMan) [Computer program]. Version 5.4 (2020) The Cochrane Collaboration.

15. Higgins JPT, Altman DG, Gotzsche PC, et al. (2011) Cochrane Bias Methods Group Cochrane Statistical Methods Group. The Cochrane Collaboration's tool for assessing risk of bias in randomised trials. BMJ 343: d5928.

16. Slim K, Nini E, Forestier D, Kwiatkowski F, Panis Y, Chipponi J. (2003) Methodological index for nonrandomized studies (minors): development and validation of a new instrument. ANZ J Surg. 73(9):712716. 
Table-1: Search Strategy

\begin{tabular}{|c|c|}
\hline $\begin{array}{l}\text { MEDLINE } \\
\text { (PubMed) }\end{array}$ & 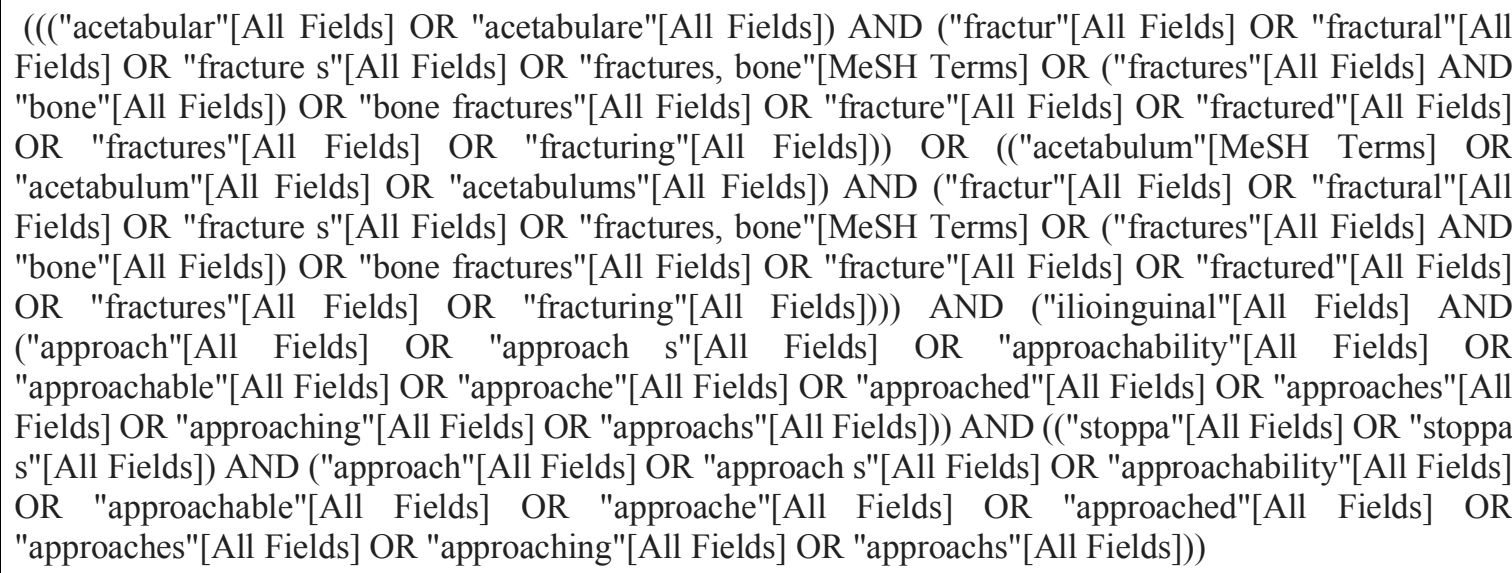 \\
\hline & $\begin{array}{l}\text { (ALL (acetabular AND fracture) OR ALL (acetabulum AND fracture) AND ALL (ilioinguinal AND appro } \\
\text { ach) AND ALL (stoppa AND approach)) }\end{array}$ \\
\hline Sc & $\begin{array}{l}\text { (ALL (acetabular AND fracture) OR ALL ( acetabulum AND fracture ) AND ALL ( ilioinguinal AND a } \\
\text { pproach ) AND ALL ( stoppa AND approach ) ) }\end{array}$ \\
\hline $\begin{array}{l}\text { Cochran } \\
\text { Library }\end{array}$ & $\begin{array}{l}\text { ure in All Text OR acetabulum fracture in All Text AND ilioinguinal approach in All Text } \\
\text { oroach in All Text - (Word variations have been searched) }\end{array}$ \\
\hline
\end{tabular}


APPENDIX 1: PRISMA-P (Preferred Reporting Items for Systematic review and Meta-Analysis Protocols) 2015 checklist: recommended items to address in a systematic review protocol*

\begin{tabular}{|c|c|c|c|}
\hline Section and topic & $\begin{array}{c}\text { Item } \\
\text { No }\end{array}$ & Checklist item & $\begin{array}{c}\text { Page } \\
\text { Number }\end{array}$ \\
\hline \multicolumn{4}{|c|}{ ADMINISTRATIVE INFORMATION } \\
\hline Title: & & $\begin{array}{l}\text { Ilioinguinal versus modified modified Stoppa approach for open reduction and } \\
\text { internal fixation of displaced acetabular fractures: A Protocol for Systematic } \\
\text { Review and Meta-Analysis }\end{array}$ & 1,2 \\
\hline Identification & $1 \mathrm{a}$ & Identify the report as a protocol of a systematic review & 1,2 \\
\hline Update & $1 b$ & If the protocol is for an update of a previous systematic review, identify as such & NA \\
\hline Registration & 2 & $\begin{array}{l}\text { If registered, provide the name of the registry (such as PROSPERO) and } \\
\text { registration number }\end{array}$ & NA \\
\hline Authors: & & $\begin{array}{l}\text { Amit Srivastava, Rajesh Kumar Rajnish, Prasoon Kumar, Rehan UI Haq, Ish Kumar } \\
\text { Dhammi }\end{array}$ & 1 \\
\hline Contact & $3 a$ & $\begin{array}{l}\text { Provide name, institutional affiliation, e-mail address of all protocol authors; } \\
\text { provide physical mailing address of corresponding author }\end{array}$ & 1 \\
\hline Contributions & $3 b$ & $\begin{array}{l}\text { Describe contributions of protocol authors and identify the guarantor of the } \\
\text { review }\end{array}$ & 1 \\
\hline Amendments & 4 & $\begin{array}{l}\text { If the protocol represents an amendment of a previously completed or published } \\
\text { protocol, identify as such and list changes; otherwise, state plan for documenting } \\
\text { important protocol amendments }\end{array}$ & NA \\
\hline \multicolumn{4}{|l|}{ Support: } \\
\hline Sources & $5 a$ & Indicate sources of financial or other support for the review & 1 \\
\hline Sponsor & $5 b$ & Provide name for the review funder and/or sponsor & 1 \\
\hline $\begin{array}{l}\text { Role of } \\
\text { sponsor or } \\
\text { funder }\end{array}$ & $5 c$ & $\begin{array}{l}\text { Describe roles of funder(s), sponsor(s), and/or institution(s), if any, in developing } \\
\text { the protocol }\end{array}$ & NA \\
\hline \multicolumn{4}{|l|}{ INTRODUCTION } \\
\hline Rationale & 6 & Describe the rationale for the review in the context of what is already known & 3 \\
\hline Objectives & 7 & $\begin{array}{l}\text { Provide an explicit statement of the question(s) the review will address with } \\
\text { reference to participants, interventions, comparators, and outcomes (PICO) }\end{array}$ & 3,4 \\
\hline \multicolumn{4}{|l|}{ METHODS } \\
\hline Eligibility criteria & 8 & $\begin{array}{l}\text { Specify the study characteristics (such as PICO, study design, setting, time frame) } \\
\text { and report characteristics (such as years considered, language, publication status) } \\
\text { to be used as criteria for eligibility for the review }\end{array}$ & 4 \\
\hline $\begin{array}{l}\text { Information } \\
\text { sources }\end{array}$ & 9 & $\begin{array}{l}\text { Describe all intended information sources (such as electronic databases, contact } \\
\text { with study authors, trial registers or other grey literature sources) with planned } \\
\text { dates of coverage }\end{array}$ & 4 \\
\hline Search strategy & 10 & $\begin{array}{l}\text { Present draft of search strategy to be used for at least one electronic database, } \\
\text { including planned limits, such that it could be repeated }\end{array}$ & \begin{tabular}{|c|} 
Table 1, \\
Page 8 \\
\end{tabular} \\
\hline \multicolumn{4}{|l|}{ Study records: } \\
\hline $\begin{array}{l}\text { Data } \\
\text { management }\end{array}$ & $11 a$ & $\begin{array}{l}\text { Describe the mechanism(s) that will be used to manage records and data } \\
\text { throughout the review }\end{array}$ & 5 \\
\hline $\begin{array}{l}\text { Selection } \\
\text { process }\end{array}$ & $11 b$ & $\begin{array}{l}\text { State the process that will be used for selecting studies (such as two independent } \\
\text { reviewers) through each phase of the review (that is, screening, eligibility and } \\
\text { inclusion in meta-analysis) }\end{array}$ & 4 \\
\hline
\end{tabular}


medRxiv preprint doi: https://doi.org/10.1101/2021.06.22.21259315; this version posted June 25,2021 . The copyright holder for this preprint (which was not certified by peer review) is the author/funder, who has granted medRxiv a license to display the preprint in perpetuity.

All rights reserved. No reuse allowed without permission.

\begin{tabular}{|c|c|c|c|}
\hline $\begin{array}{l}\text { Data collection } \\
\text { process }\end{array}$ & $11 \mathrm{c}$ & $\begin{array}{l}\text { Describe planned method of extracting data from reports (such as piloting forms, } \\
\text { done independently, in duplicate), any processes for obtaining and confirming } \\
\text { data from investigators }\end{array}$ & 5 \\
\hline Data items & 12 & $\begin{array}{l}\text { List and define all variables for which data will be sought (such as PICO items, } \\
\text { funding sources), any pre-planned data assumptions and simplifications }\end{array}$ & 5 \\
\hline $\begin{array}{l}\text { Outcomes and } \\
\text { prioritization }\end{array}$ & 13 & $\begin{array}{l}\text { List and define all outcomes for which data will be sought, including prioritization } \\
\text { of main and additional outcomes, with rationale }\end{array}$ & 5 \\
\hline $\begin{array}{l}\text { Risk of bias in } \\
\text { individual studies }\end{array}$ & 14 & $\begin{array}{l}\text { Describe anticipated methods for assessing risk of bias of individual studies, } \\
\text { including whether this will be done at the outcome or study level, or both; state } \\
\text { how this information will be used in data synthesis }\end{array}$ & 6 \\
\hline \multirow[t]{4}{*}{ Data synthesis } & $15 a$ & Describe criteria under which study data will be quantitatively synthesised & 5 \\
\hline & $15 b$ & $\begin{array}{l}\text { If data are appropriate for quantitative synthesis, describe planned summary } \\
\text { measures, methods of handling data and methods of combining data from } \\
\text { studies, including any planned exploration of consistency (such as } I^{2} \text {, Kendall's } \tau \text { ) }\end{array}$ & 5 \\
\hline & $15 c$ & $\begin{array}{l}\text { Describe any proposed additional analyses (such as sensitivity or subgroup } \\
\text { analyses, meta-regression) }\end{array}$ & $\begin{array}{c}\text { Not } \\
\text { Planned }\end{array}$ \\
\hline & $15 d$ & $\begin{array}{l}\text { If quantitative synthesis is not appropriate, describe the type of summary } \\
\text { planned }\end{array}$ & NA \\
\hline Meta-bias(es) & 16 & $\begin{array}{l}\text { Specify any planned assessment of meta-bias(es) (such as publication bias across } \\
\text { studies, selective reporting within studies) }\end{array}$ & $\begin{array}{c}\text { Not } \\
\text { Planned }\end{array}$ \\
\hline $\begin{array}{l}\text { Confidence in } \\
\text { cumulative } \\
\text { evidence }\end{array}$ & 17 & $\begin{array}{l}\text { Describe how the strength of the body of evidence will be assessed (such as } \\
\text { GRADE) }\end{array}$ & $\begin{array}{l}\text { Not } \\
\text { Planned }\end{array}$ \\
\hline
\end{tabular}

* It is strongly recommended that this checklist be read in conjunction with the PRISMA-P Explanation and Elaboration (cite when available) for important clarification on the items. Amendments to a review protocol should be tracked and dated. The copyright for PRISMA-P (including checklist) is held by the PRISMA-P Group and is distributed under a Creative Commons Attribution Licence 4.0.

From: Shamseer L, Moher D, Clarke M, Ghersi D, Liberati A, Petticrew M, Shekelle P, Stewart L, PRISMA-P Group. Preferred reporting items for systematic review and meta-analysis protocols (PRISMA-P) 2015: elaboration and explanation. BMJ. 2015 Jan 2;349(jan02 1):g7647. 